\title{
Abnormal plasma polyunsaturated fatty acid pattern in non-active inflammatory bowel disease
}

\author{
M Esteve-Comas, M C Núñez, F Fernández-Bañares, A Abad-Lacruz, A Gil, E Cabré, \\ F González-Huix, X Bertrán, M A Gassull
}

\begin{abstract}
An abnormal plasma polyunsaturated fatty acid pattern (PUFA) (increased $\mathrm{n} 3$ and decreased n6 PUFA) has been reported in active inflammatory bowel disease (IBD). The possibility of a primary defect in the PUFA metabolism in IBD was hypothesised. The aim of this study was to assess plasma PUFA pattern in inactive inflammatory bowel disease and to ascertain whether patients who had had a colectomy and who were suffering from ulcerative colitis have a similar PUFA pattern than those patients with non-active ulcerative colitis and who had not had a colectomy. Plasma fatty acids were analysed by semicapillary column gas-liquid chromatography in three groups of patients with inactive IBD (24 patients with inactive ulcerative colitis who had not had a colectomy, 15 patients with ulcerative colitis who had had a colectomy, and 27 patients with Crohn's disease). Plasma concentration and percentage of $\mathrm{C} 22: 6 \mathrm{n} 3$ and unsaturation index were significantly higher in patients with inactive ulcerative colitis without a colectomy and the Crohn's disease group $(\mathbf{p}<0.0001)$ than in controls. Plasma concentration and percentage of $\mathrm{C} 22: 6 \mathrm{n} 3$ and the unsaturation index remained significantly higher, in both the operated and non-operated ulcerative colitis patients when compared with controls $(p<0.0001)$. These results suggest that in inactive IBD, an increased PUFA biosynthesis might be the cause of the high values of $n 3$ compounds. These findings although seen in active disease, are more noticeable in remission because of the lack of artefactual factors (malnutrition, steroids, inflammation). In addition, persistence of high values in both groups of ulcerative colitis patients - that is, those who had had a colectomy and those who had not suggests the existence of a primary abnormality in the PUFA metabolism in IBD. (Gut 1993; 34: 1370-1373)
\end{abstract}

Polyunsaturated fatty acids (PUFA) participate in membrane function, ${ }^{12}$ including that of the immune cells ${ }^{34}$ and they are precursors of the eicosanoids. ${ }^{5-8}$ For these reasons, they may play an important part in the pathogenesis of inflammatory bowel disease (IBD).

We have described an abnormal PUFA pattern in active IBD. ${ }^{9}$ This consists of increased values of the precursor $(\mathrm{C18:3n} 3)$ and the end product $(C 22 ; 6 n 3)$ of the $n 3$ series and decreased values of dihommo- $\gamma$-linolenic acid (C20:3n6). A stepwise decrease in PUFA values, which was more noticeable for the $\mathrm{n} 6$ series was also seen as the disease became more severe. Even in severe disease, however, plasma concentrations of the n3 PUFA remained higher than those in healthy controls. These findings suggested that in IBD there might be a primary increase in PUFA biosynthesis. In active IBD this phenomenon would be partly counterbalanced by an increased fatty acid utilisation because of factors associated with disease activity, such as inflammation, hypermetabolism, malnutrition, and steroid treatment.

On the basis of the above findings, it could be hypothesised that in the absence of other factors, that is in inactive disease, the values of long chain PUFA would be even higher. Therefore, the study of patients with inactive IBD would be of interest. In addition, to ascertain the possible existence of a primary defect in PUFA metabolism, the study of patients with ulcerative colitis who had had a colectomy would be particularly important, as in such patients, the target organ has been removed. The aim of this study was to assess prospectively the plasma fatty acid pattern in patients with inactive IBD (both ulcerative colitis and Crohn's disease), and in ulcerative colitis patients after colectomy.

\section{Patients and methods}

PATIENTS

Three groups of 66 patients with inactive IBD were included in the study: 27 Crohn's disease (16 men, 11 women; median age 24 years; ranges 14-78 years), 24 ulcerative colitis patients (10 men, 14 women; median age 41 years; range: 23-75 years) and 15 patients with ulcerative colitis who had had a colectomy, four procto-

\begin{tabular}{|c|c|c|c|}
\hline & $\begin{array}{l}\text { Patients with } \\
\text { UC (no } \\
\text { colectomy) } \\
(n=24)\end{array}$ & $\begin{array}{l}\text { Patients with } \\
\text { UC } \\
\text { (colectomy) } \\
(n=15)\end{array}$ & $\begin{array}{l}C D \\
(n=27)\end{array}$ \\
\hline \multicolumn{4}{|l|}{$\begin{array}{l}\text { Location of the disease in } \\
\text { previous attacks }\end{array}$} \\
\hline \multicolumn{4}{|l|}{ Ulcerative colitis } \\
\hline $\begin{array}{l}\text { Rectum } \\
\text { Left colon }\end{array}$ & $\begin{array}{r}6 \\
12\end{array}$ & & \\
\hline Universal & 6 & 15 & \\
\hline \multicolumn{4}{|l|}{ Crohn's disease } \\
\hline Small bowel & & & 7 \\
\hline Colon & & & 11 \\
\hline Ileum + colon & & & 9 \\
\hline \multicolumn{4}{|l|}{ Current drug treatment } \\
\hline Metronidazole & 0 & 2 & 4 \\
\hline Sulphasalazine & 16 & 0 & 9 \\
\hline 5-ASA & 8 & 0 & 4 \\
\hline \multicolumn{4}{|l|}{ Nutritional state ${ }^{12}$} \\
\hline Well nourished & 23 & 12 & 24 \\
\hline Kwashiorkor like & 0 & 1 & 2 \\
\hline Marasmus & 1 & 2 & $\overline{1}$ \\
\hline Mixed malnutrition & 0 & 0 & 0 \\
\hline
\end{tabular}

$\mathrm{UC}=$ ulcerative colitis, $\mathrm{CD}=\mathrm{Crohn}$ 's disease .

\author{
Correspondence to: \\ Dr M A Gassull, Head of the \\ Department of \\ Gastroenterology, Hospital \\ Universitari 'Germans Trias \\ Pujol', Carretera del Canyet \\ $\mathrm{s} / \mathbf{n}, 08916$ Badalona, Spain \\ Accepted for publication \\ 9 February 1993 \\ Department of
Gastroenterology, \\ Hospital Universitari \\ Badalona, Spain \\ F Fernández-Bañares \\ A Abad- \\ F González- \\ Research Department of \\ UNIA \\ MCNúñez
}


TABLE II Plasma fatty acids in inactive inflammatory bowel disease

\begin{tabular}{|c|c|c|c|c|}
\hline umol/dl & $U C(n=24)$ & $C D(n=27)$ & Controls $(n=107)$ & $p$ \\
\hline $16: 0^{\star}$ & $155 \cdot 6 \quad(6 \cdot 1)$ & $126.0(4.9)$ & $128 \cdot 9(3 \cdot 4)$ & $0.0012 \ddagger \|$ \\
\hline 16:1† & $8 \cdot 5 \quad(6 \cdot 6-12 \cdot 9)$ & $10.8(6.8-15 \cdot 3)$ & $8 \cdot 4(8 \cdot 1-9 \cdot 5)$ & 0.5641 \\
\hline $18: 0^{\star}$ & $60 \cdot 1 \quad(2 \cdot 8)$ & $51.9(2.3)$ & $53 \cdot 2(1 \cdot 3)$ & 0.0649 \\
\hline $18: 1^{\star}$ & $118 \cdot 3 \quad(7 \cdot 0)$ & $104 \cdot 2(5 \cdot 4)$ & $110 \cdot 6(3 \cdot 2)$ & $0 \cdot 3042$ \\
\hline $18: 2 \mathrm{n} 6^{\star}$ & $169 \cdot 1 \quad(9 \cdot 0)$ & $138.4(6.5)$ & $137.6(3.9)$ & $0.0030 \ddagger$ \\
\hline $18: 3 n 3 \dagger$ & $2 \cdot 1 \quad(0 \cdot 0-5 \cdot 9)$ & $0.0(0.0-5 \cdot 5)$ & $0.0(0.0-0.0)$ & $0.0499 \ddagger$ \\
\hline $18: 3 n 6 \dagger$ & $0.0 \quad(0.0-1.6)$ & $0.0(0.0-1.8)$ & $0.0(0.0-0.0)$ & 0.2223 \\
\hline $20: 2 n 6 \dagger$ & $0.5 \quad(0 \cdot 0-2 \cdot 1)$ & $0.0(0 \cdot 0-2 \cdot 2)$ & $1 \cdot 0(0 \cdot 0-1 \cdot 8)$ & 0.9429 \\
\hline $20: 3 n 6^{\star}$ & $15 \cdot 6 \quad(0.9)$ & $13 \cdot 7(0 \cdot 8)$ & $13 \cdot 3(0 \cdot 5)$ & $0 \cdot 1212$ \\
\hline $20: 4 n 6^{\star}$ & $52.0 \quad(2.6)$ & $43.6(1.9)$ & $40 \cdot 6(1 \cdot 4)$ & $0.0021 \ddagger$ \\
\hline $20: 5 n 3 t$ & $1.8 \quad(0.0-3.1)$ & $1 \cdot 3(0 \cdot 0-2 \cdot 7)$ & $0.7(0.0-1 \cdot 7)$ & 0.6049 \\
\hline $22: 6 n 3^{\star}$ & $16 \cdot 75(11 \cdot 71-19.75)$ & $11 \cdot 6(11 \cdot 17-19 \cdot 68)$ & $7 \cdot 0(6 \cdot 1-7 \cdot 9)$ & $<0.00001 \neq \varnothing$ \\
\hline
\end{tabular}

${ }^{\star}$ Mean (SEM). One way ANOVA+Scheffé test; †median (95\% CI), Kruskall-Wallis test+MannWhitney U test; $\ddagger \mathrm{UC} v$ controls; $\ C D v$ controls; $\| C D v$ UC. Other abbreviations as in Table I.

TABLE III Plasma fatty acids in inactive inflammatory bowel disease

\begin{tabular}{|c|c|c|c|c|}
\hline$\%$ & $U C(n=24)$ & $C D(n=27)$ & Controls $(n=107)$ & $p$ \\
\hline $16: 0^{\star}$ & $25 \cdot 7(0 \cdot 3)$ & $24 \cdot 3(0 \cdot 4)$ & $25 \cdot 2(0 \cdot 2)$ & 0.0515 \\
\hline $16: 1 \dagger$ & $1 \cdot 4(0 \cdot 9-2 \cdot 1)$ & $2 \cdot 2(1 \cdot 3-3 \cdot 1)$ & $1 \cdot 7(1.5-1.9)$ & $0 \cdot 1456$ \\
\hline $18: 0^{\star}$ & $9.9(0.2)$ & $10 \cdot 0(0 \cdot 3)$ & $10 \cdot 5(0 \cdot 1)$ & 0.0811 \\
\hline $18: 1^{\star}$ & $19 \cdot 4(0.7)$ & $20.0(0.6)$ & $21 \cdot 7(0 \cdot 3)$ & $0.0061 \ddagger$ \\
\hline $18: 2 \mathrm{n} 6^{\star}$ & $27.8(0.9)$ & $26.9(1.0)$ & $27 \cdot 2(0 \cdot 4)$ & 0.7817 \\
\hline $18: 3 n 3 t$ & $0.3(0 \cdot 0-1 \cdot 0)$ & $0.0(0.0-0.9)$ & $0.0(0.0-0.0)$ & 0.0815 \\
\hline $18: 3 n 6 \dagger$ & $0.0(0.0-0.2)$ & $0.0(0.0-0.3)$ & $0.0(0.0-0.0)$ & $0 \cdot 2480$ \\
\hline $20: 2 n 6 \dagger$ & $0.1(0.0-0.3)$ & $0.0(0.0-0.4)$ & $0.1(0.0-0.3)$ & 0.5297 \\
\hline $20: 3 n 6^{\star}$ & $2 \cdot 5(0 \cdot 1)$ & $2 \cdot 6(0 \cdot 1)$ & $2 \cdot 6(0 \cdot 1)$ & 0.9068 \\
\hline $20: 4 n 6^{\star}$ & $8 \cdot 6(0.3)$ & $8.4(0.3)$ & $8.0(0.2)$ & 0.4427 \\
\hline $20: 5 n 3 t$ & $0.2(0.0-0.5)$ & $0.2(0.0-0.6)$ & $0.2(0.0-0.3)$ & $0 \cdot 8298$ \\
\hline $22: 6 n 3 t$ & $2.6(1.9-3.5)$ & $2 \cdot 4(2 \cdot 3-3 \cdot 3)$ & $1 \cdot 4(1 \cdot 3-1 \cdot 6)$ & $<0.00001 \neq \S$ \\
\hline $\mathrm{UNID}^{\star}$ & $141 \cdot 1(1 \cdot 7)$ & $140.7(1.8)$ & $131 \cdot 5(1 \cdot 1)$ & $0.00010 \neq$ \\
\hline
\end{tabular}

${ }^{\star}$ Mean (SEM). One way ANOVA+Scheffé test; tmedian (95\% CI), Kruskall-Wallis test + MannWhitney U test; $\ddagger U C \mathrm{U} v$ controls; $\ C D v$ controls. UNID = unsaturation index. Other abbreviations as in Table I.

colectomy and 11 colectomy plus ileal pelvic pouch (eight men, seven women; median age 31 years, range: 15-46 years). Patients were considered inactive as assessed by the Truelove and Witts' index ${ }^{10}$ for ulcerative colitis and the Van Hess' index ${ }^{11}$ for Crohn's disease. No patient with ileal pelvic pouch had clinical, endoscopic, or histological signs of pouchitis. Table I shows the clinical features of the patients studied. ${ }^{12}$ The results of the fatty acid state of all of these patients had been reported previously in active phase. ${ }^{9}$

\section{CONTROLS}

A previously reported group of 107 healthy, well nourished subjects (46 men, 61 women; median age: 32.5 years; ranges $18-76$ years) acted as a control group. ${ }^{9}$

Informed consent was obtained from each patient and healthy controls. The study was performed in conformance with the 1975 Declaration of Helsinki ethical guidelines and was approved by the Research and Ethical Committees of the Hospital.

\section{PLASMA FATTY ACID ASSAY}

In all patients and healthy controls, a $5 \mathrm{ml}$ venous blood sample for plasma fatty acid measurement was taken after a 14 hour overnight fast. Blood samples in all ulcerative colitis and Crohn's disease patients were obtained three months after they had been considered inactive and in ulcerative colitis patients who had had a colectomy between three to six months after completion of all operations. The methods used for plasma fatty acid assay have been described in detail elsewhere. ${ }^{9131+}$ Heptadecanoic acid (C17:0) was added as an internal standard to allow fatty acid concentrations in plasma total lipids to be determined as absolute values, and not only as percentages.

Fatty acid from 14:0 to $22: 6$ n 3 were measured. Unidentified peaks accounted for less than $0.5 \%$ of the total fatty acid. Results are expressed as a total fatty acid concentration $(\mu \mathrm{mol} / \mathrm{dl})$ and as a percentage distribution of each fatty acid. The unsaturation index (UNID) was calculated according to the formula ${ }^{15}$ :

$$
\begin{aligned}
& \text { UNID }=\Sigma(\text { fatty acid percentage } \times \\
& \text { number of double bonds). }
\end{aligned}
$$

\section{STATISTICAL ANALYSIS}

For statistical analysis the Statistical Package for Social Sciences SPSS/PC+ (SPSS Inc, Chicago, Illinois, 1985) was used. ${ }^{16}$ Variables with normal distribution and homogeneous variance were compared by means of parametric tests, otherwise their non-parametric counterparts were used. One way analysis of variance with 'a posterior' Scheffé test or Kruskall-Wallis one way analysis of variance by ranks were used. When the Kruskall-Wallis test disclosed a significant $p$ value, the Mann-Whitney $U$ test was carried out to detect where the differences occurred. Results are expressed as mean (SEM) or median and the $95 \%$ confidence intervals $(\mathrm{CI})^{17}$ for parametric and non-parametric variables respectively. Because age distribution was different among the groups studied and this is a factor influencing plasma lipids, ${ }^{18}$ the results were adjusted for the effect of age by means of analysis of variance using age as a covariate.

\section{Results}

PLASMA FATTY ACIDS IN INACTIVE INFLAMMATORY BOWEL DISEASE

Tables II and III detail respectively the plasma fatty acid concentration and the percentages of the different fatty acids in patients with inactive ulcerative colitis and Crohn's disease.

The most striking finding in the plasma fatty acid profile in inactive IBD was the considerable increase of docosahexaenoic acid (C22:6n3), the final product of the $n 3$ series, both in ulcerative colitis and Crohn's disease when compared with controls. This fact was seen when the results were expressed either as absolute concentration or as a percentage.

Arachidonic acid (C20:4n6), the main product of the n6 series, showed the same tendency. Statistical significance was only obtained, however, between the ulcerative colitis patients and controls, when the values were expressed as absolute plasma concentration. Absolute plasma values of linoleic acid (C18:2n6), the essential precursor of the $n 6$ series, and $\alpha$-linolenic acid (C18:3n3), the essential precursor of the n3 series, were also increased in ulcerative colitis (Table II).

As a consequence of the increase in long chain and highly unsaturated PUFA, the values of the 
TABLE IV Plasma fatty acids in inactive ulcerative colitis. Influence of the colectomy on the plasma fatty acid pattern

\begin{tabular}{|c|c|c|c|c|}
\hline \multirow[b]{2}{*}{ $\mu \mathrm{mol} / \mathrm{dl}$} & \multicolumn{2}{|l|}{ UC patients } & \multirow[b]{2}{*}{$\begin{array}{l}\text { Controls } \\
(n=107)\end{array}$} & \multirow[b]{2}{*}{$p$} \\
\hline & $\begin{array}{l}\text { Operated } \\
(n=15)\end{array}$ & $\begin{array}{l}\text { Non-operated } \\
(n=24)\end{array}$ & & \\
\hline $\begin{array}{l}16: 0^{\star} \\
16: 1 \dagger \\
18: 0^{\star} \\
18: 1^{\star} \\
18: 2 \mathrm{n} 6^{\star} \\
18: 3 \mathrm{n} 3 \dagger \\
18: 3 \mathrm{n} 6 \dagger \\
20: 2 \mathrm{n} 6 \dagger \\
20: 3 \mathrm{n} 6^{\star} \\
20: 4 \mathrm{n} 6^{\star} \\
20: 5 \mathrm{n} 3 \dagger \\
22: 6 \mathrm{n} 3^{\star}\end{array}$ & $\begin{array}{c}121 \cdot 3(7 \cdot 3) \\
6 \cdot 6(1 \cdot 0-10 \cdot 3) \\
52 \cdot 2(2 \cdot 2) \\
90 \cdot 1(6 \cdot 6) \\
147 \cdot 5(8 \cdot 6) \\
0 \cdot 0(0 \cdot 0-4 \cdot 9) \\
0 \cdot 0(0 \cdot 0-1 \cdot 9) \\
0 \cdot 0(0 \cdot 0-2 \cdot 3) \\
12 \cdot 7(1 \cdot 4) \\
45 \cdot 4(2 \cdot 4) \\
0 \cdot 0(0 \cdot 0-2 \cdot 3) \\
13 \cdot 9(9 \cdot 6-16.1)\end{array}$ & $\begin{array}{l}155 \cdot 6(6 \cdot 1) \\
8 \cdot 5(6 \cdot 6-12 \cdot 9) \\
60 \cdot 1(2 \cdot 8) \\
118 \cdot 3(7 \cdot 0) \\
169 \cdot 1(9 \cdot 0) \\
2 \cdot 1(0 \cdot 0-5 \cdot 9) \\
0 \cdot 0(0 \cdot 0-1 \cdot 6) \\
0 \cdot 5(0 \cdot 0-2 \cdot 1) \\
15 \cdot 6(0 \cdot 9) \\
52 \cdot 0(2 \cdot 6) \\
1 \cdot 8(0 \cdot 0-3 \cdot 1) \\
16 \cdot 7(11 \cdot 7-19 \cdot 7)\end{array}$ & $\begin{array}{c}128.9(3.4) \\
8.4(8 \cdot 1-9 \cdot 5) \\
53.2(1.3) \\
110.6(3.2) \\
137.6(3.9) \\
0.0(0 \cdot 0-0.0) \\
0.0(0 \cdot 0-0.0) \\
1.0(0 \cdot 0-1 \cdot 8) \\
13.3(0.5) \\
40.6(1.4) \\
0.7(0.0-1.7) \\
7.0(6.1-7.9)\end{array}$ & $\begin{array}{l}0.0013 \S \| \\
0.1631 \\
0.0615 \\
0.0319 \| \\
0.0037 \$ \\
0.0808 \\
0.3176 \\
0.7593 \\
0.1082 \\
0.0022 \$ \\
0.6853 \\
<0.00001 \ddagger \varnothing \|\end{array}$ \\
\hline
\end{tabular}

*Mean (SEM). One way ANOVA+Scheffé test; †median (95\% CI), Kruskall-Wallis test +MannWhitney U test; ‡operated $v$ controls; [non-operated $v$ controls; $\|$ operated $v$ non-operated.

TABLE v Plasma fatty acids in inactive ulcerative colitis. Influence of the colectomy on the plasma fatty acid pattern

\begin{tabular}{|c|c|c|c|c|}
\hline \multirow[b]{2}{*}{$\%$} & \multicolumn{2}{|l|}{ UC patients } & \multirow[b]{2}{*}{$\begin{array}{l}\text { Controls } \\
(n=107)\end{array}$} & \multirow[b]{2}{*}{$p$} \\
\hline & $\begin{array}{l}\text { Operated } \\
(n=15)\end{array}$ & $\begin{array}{l}\text { Non-operated } \\
(n=24)\end{array}$ & & \\
\hline $16: 0^{\star}$ & $24.4(0.5)$ & $25 \cdot 7(0 \cdot 3)$ & $25 \cdot 2(0 \cdot 2)$ & $0 \cdot 2147$ \\
\hline $16: 1+$ & $1 \cdot 2(0 \cdot 2-2 \cdot 1)$ & $1.4(0.9-2 \cdot 1)$ & $1.7(1.5-1.9)$ & $0.0236 \neq$ \\
\hline $18: 0^{\star}$ & $10.7(0.3)$ & $9 \cdot 9(0 \cdot 2)$ & $10 \cdot 5(0 \cdot 1)$ & $0.2266^{\top}$ \\
\hline $18: 1^{\star}$ & $18 \cdot 1(0 \cdot 7)$ & $19 \cdot 4(0 \cdot 7)$ & $21 \cdot 7(0 \cdot 3)$ & $0 \cdot 0002 \ddagger \varnothing$ \\
\hline $18: 2 n 6^{\star}$ & $29.9(1.0)$ & $27 \cdot 8(0.9)$ & $27 \cdot 2(0 \cdot 4)$ & 0.0918 \\
\hline $18: 3 n 3 t$ & $0.3(0.0-1 \cdot 2)$ & $0.3(0.0-1 \cdot 0)$ & $0.0(0.0-0.0)$ & $0 \cdot 1199$ \\
\hline $18: 3 n 6+$ & $0.0(0.0-0.4)$ & $0.0(0.0-0.2)$ & $0.0(0.0-0.0)$ & 0.3530 \\
\hline $20: 2 n 6 t$ & $0.0(0.0-0.4)$ & $0 \cdot 1(0 \cdot 0-0 \cdot 3)$ & $0 \cdot 1(0.0-0 \cdot 3)$ & 0.3782 \\
\hline $20: 3 n 6 t$ & $2 \cdot 6(2 \cdot 0-3 \cdot 3)$ & $2 \cdot 4(2 \cdot 2-2 \cdot 9)$ & $2 \cdot 5(2 \cdot 3-2 \cdot 8)$ & 0.9194 \\
\hline $20: 4 n 6 \dagger$ & $9 \cdot 1(8 \cdot 3-10 \cdot 6)$ & $8.6(7.9-9.9)$ & $7 \cdot 8(7 \cdot 1-8 \cdot 7)$ & 0.0625 \\
\hline $20: 5 n 3 t$ & $0.0(0.0-0.9)$ & $0.2(0.0-0.5)$ & $0.2(0.0-0.3)$ & 0.9017 \\
\hline $22: 6 n 3 t$ & $2 \cdot 3(1 \cdot 8-2.8)$ & $2 \cdot 6(1 \cdot 9-3 \cdot 5)$ & $1 \cdot 4(1 \cdot 3-1 \cdot 6)$ & $<0.00001 \mp \varnothing$ \\
\hline UNID * & $142 \cdot 0(1 \cdot 7)$ & $141 \cdot 7(1 \cdot 7)$ & $131 \cdot 5(1 \cdot 1)$ & $<0.00001 \neq \varnothing$ \\
\hline
\end{tabular}

${ }^{\star}$ Mean (SEM). One way ANOVA+Scheffé test; tmedian (95\% CI), Kruskall-Wallis test+MannWhitney $\mathrm{U}$ test; łoperated $v$ controls; §non-operated $v$ controls. UNID = unsaturation index.

UNID were also significantly high, both in inactive ulcerative colitis and Crohn's disease, compared with controls (Table III).

Changes in saturated and monoenoic fatty acids depended on a diminished percentage of oleic acid (C18: $\ln 9)$ and an increased concentration of palmitic acid (C16:0) in ulcerative colitis with respect to the control group and an increased percentage of palmitoleic acid (C16:1) in Crohn's disease (Table III).

After adjusting for age as described in the statistical methods section, the significance of the differences seen did not change.

INFLUENCE OF COLECTOMY FOR ULCERATIVE COLITIS ON PLASMA FATTY ACID PATTERN

(Tables IV and V)

Plasma docosahexaenoic acid (C22:6n3), either as a percentage or an absolute concentration, was significantly higher both in operated and nonoperated ulcerative colitis patients when compared with controls. In addition, when expressed as plasma concentration, C22:6n 3 was significantly higher in non-operated than in operated patients (Table IV). UNID was also significantly increased in both groups of patients compared with controls (Table V).

In the n6 series, the plasma concentration of linoleic (C18:2n6) and arachidonic acid (C20:4n6) was only significantly increased in non-operated ulcerative colitis patients with respect to the control group, although the same trend was seen for the operated group.

The increase of plasma long chain PUFA content in both groups of patients was associated with a significant decrease in the percentage of oleic acid $(\mathrm{C} 18: \ln 9)$ in both groups of patients and by the reduction in the percentage of palmitoleic acid $(\mathrm{C} 16: \ln 7)$ in operated patients (Table V).

After adjusting for the effect of age, the results did not change except for the oleic acid concentration, which showed no differences among the three groups $(p=0 \cdot 151)$.

\section{Discussion}

Before discussing the results of this study, an aspect of the methods used has to be noted. Fatty acid values in this paper are expressed both as a percentage of the total fatty acids and as an absolute plasma concentration. Expressing the results as plasma concentration permitted us to show that any change in a given fatty acid is real, whereas its percentage may only reflect compensatory changes because of increases or decreases in other fatty acids. The results, however, should also be given as a percentage distribution. This provides complementary information, as it helps to ascertain whether changes in the plasma concentrations result in variations in the relative amounts of fatty acids - that is, in qualitative changes of plasma lipids.

In a previous paper, ${ }^{9}$ we reported increased n3 and decreased n6 PUFA values in active IBD. It was then hypothesised that in active IBD a primary enhancement in PUFA synthesis coexisted with an increased utilisation related to the inflammatory phenomena. In this series of inactive IBD patients, plasma n3 PUFA are also increased. This, together with high values of $n 6$ PUFA and UNID, in the absence of factors associated with active disease, further supports this hypothesis. The fact that high n3 PUFA values occur in both active and non-active disease can be explained because $n 3$ series has the highest affinity for PUFA biosynthetic enzyme systems. ${ }^{19} 20$

The increase in $n 6$ long chain PUFA is particularly noticeable in non-active, non-operated ulcerative colitis patients, their values being significantly higher than those in healthy controls. Also, significantly increased values of the precursors of both $\mathrm{n} 3(\mathrm{C} 18: 3 \mathrm{n} 3)$ and $n 6$ (C18:2n6) series were seen in this group of patients. As a high intake of essential fatty acids, particularly of $\alpha$-linolenic acid (C18:3n3), was ruled out in all cases, this finding could be attributed to a negative feedback effect ${ }^{21-23}$ upon $\delta-6$ desaturase activity, caused by the excessive amount of products of both $n 3(\mathrm{C} 22: 6 \mathrm{n} 3)$ and $n 6$ series (C20:4n6). From these data, it could be speculated that the hypothesis of an increased PUFA biosynthesis is more active in ulcerative colitis than in Crohn's disease patients.

Differences in age distribution may account, at least in part, for the differences seen in plasma fatty acid concentrations between operated and non-operated patients and between ulcerative colitis patients and controls. After adjusting for 
age as a covariate, however, the significance of the results did not change, except for oleic acid concentration, which showed no differences between operated and non-operated ulcerative colitis patients.

Malnutrition may be another important factor that explains fatty acid differences among groups because PUFA deficiency has been described in malnourished patients. ${ }^{24}$ Malnutrition only occurred, however, in four (10\%) ulcerative colitis and three $(11 \%)$ Crohn's disease patients in this series. Moreover, vitamin and trace element deficiencies, which have been reported in active IBD, ${ }^{2627}$ could be additional factors influencing PUFA biosynthesis. Unfortunately, data on the micronutrient state in this series of non-active patients are not available.

A further argument in favour of the existence of an increased PUFA biosynthesis in IBD is the persistence of increased values of docosahexaenoic acid (C22:6n3) three to six months after colectomy in patients with ulcerative colitis. In addition, this finding suggests that it may be because of a primary metabolic defect. Although three to six months seems to be enough time to reach a stable state after colectomy, the possibility that plasma PUFA pattern took longer to return to normal has to be ruled out in future studies. Thus, a study comparing larger groups of patients with both proctocolectomy and colectomy plus ileal pouch patients, at least two years after the completion of surgery, has to be performed to confirm these results.

On the other hand, the hypothesis of a genetically determined primary defect in PUFA metabolism in IBD should be assessed by measuring PUFA profile in healthy relatives of IBD patients.

These results further support our reluctance to use long chain n3 PUFA in treatment for either acute attacks of IBD or for maintenance treatment of the disease.

Supported by grant $88 / 2074$ of the FISss, National Institute of Health, Spain.

1 Mead JF. The non-eicosanoid functions of the essential fatty acids $\dot{f}$ Lipid Res 1984; 25: 1517-21.

2 Spector AA, Yorek MA. Membrane lipid composition and cellular function. $\mathcal{F}$ Lipid Res 1985; 26: 1015-35.

3 Kinsella JE, Lokesh B, Broughton S, Whelan J. Dietary polyunsaturated fatty acids and eicosanoids: Potential effects on the modulation of inflammatory and immune cells: An overview. Nutrition 1990; 6: 24-44.
4 Robinson DR. Alleviation of autoimmune disease by dietary lipids containing omega-3 fatty acids. Rheum Dis Clin North Am 1991; 17: 213-22.

5 Falardeau P, Hamberg M, Samuelsson B. Metabolism of 8, 11, 14-eicosatrienoic acid in human platelets. Biochim Biophys Acta 1976; 441: 193-200.

6 Samuelsson B, Goldyne M, Granstrom E, Hamberg M, Hammarstrom S, Malmsten C. Prostaglandins and throm boxanes. Ann Rev Biochem 1978; 47: 997-1029.

7 Samuelsson B. Leukotrienes: mediators of immediate hypersensitivity reactions and inflammation. Science 1983; 220 568-75.

8 Needleman P, Raz A, Minkes MS, Ferrendelli JA, Sprecher H. Triene prostaglandins: Prostacyclin and thromboxane H. Triene prostaglandins: Prostacyclin and thromboxane
biosynthesis and unique biological properties. Proc Natl biosynthesis and unique biologica

9 Esteve-Comas M, Ramirez M, Fernández-Bañares F, AbadLacruz A, Gil A, Cabré E, et al. Plasma polyunsaturated fatty acid pattern in active inflammatory bowel disease. Gu 1992; 33: 1365-9.

10 Truelove SC, Witts LJ. Cortisone in ulcerative colitis. Final report on a therapeutic trial. $B M \mathcal{F} 1955 ; 2$ : $1041-6$.

11 Van Hees PAM, Van Elteren PH, Van Lier HJJ, Van Tongeren JHM. An index of inflammatory activity in patients with Crohn's disease. Gut 1980; 21: 279-86.

12 Gassull MA, Cabré E, Vilar L, Alastrue A, Montserrat A. Protein-energy malnutrition: An integral approach and a simple new classification. Hum Nutr Clin Nutr 1984; 38C simple new.

13 Cabré E, Periago JL, Mingorance MD, Fernández-Bañares F, Abad A, Esteve M, et al. Factors related to the plasma fatty acid profile in healthy subjects with special reference to antioxidant micronutrient status: a multivariate analysis. Am $\mathcal{F}$ Clin Nutr 1992; 55: 831-7.

14 Cabré E, González-Huix F, Abad-Lacruz A, González-Huix $\mathrm{F}$, González J, Esteve $M$, et al. Plasma fatty acid profile in advanced cirrhosis: unsaturation deficit of plasma lipid fractions. Am $\mathcal{F}$ Gastroenterol 1990; 85: 1597-604.

15 Galli C, White HB, Paoletti R. Brain lipid modifications induced by essential fatty acid deficiency in growing male and female rats. $\mathcal{F}$ Neurochem $1970 ; 17: 347-55$.

16 Norusis MJ. Advanced statistics SPSS/PC + for the IBM PC/XT/AT. Chicago: SPSS Inc, 1986.

17 Diem K, Lentner C, eds. Documenta Geigy. Scientific tables. 7th ed. Basel: Geigy, 1970.

18 Zakim D. Metabolism of glucose and fatty acids by the liver. In: Zakim and Boyer, eds. Hepatology. Vol 1. 2nd ed Philadelphia: WB Saunders, 1990: 65-96.

19 Holman RT. Nutritional and metabolic interrelationships between fatty acids. Fed Proc 1964; 23: 1062-7.

20 Brenner RR, Peluffo RO. Effect of saturated and unsaturated fatty acids on the desaturation in vitro of palmitic, stearic, oleic, linoleic and linolenic acids. $\mathcal{F}$ Biol Chem 1966; 241 : 5213-9.

21 Bivins BA, Bell RM, Rapp RP, Griffen WO. Linoleic acid versus linolenic acid: What is essential? $\mathcal{F} P E N$ 1983; 7 : 473-8.

22 Brenner RR, Peluffo RO, Nervi AM, De Tomas ME. Competitive effect of $\alpha$ - and $\tau$-linolenyl-CoA and arachidonylpoA in linoleyl-CoA desaturation to $\tau$-linolenyl-CoA Biochim Biophys Acta 1969; 176: 420-2.

23 Brenner RR, Peluffo RO. Inhibitory effect of docosa$4,7,10,13,16,19$-hexaenoic acid upon the oxidative desaturation of linoleic into $\tau$-linolenic acid and of $\alpha$-linolenic acid into octadeca-6,9,12,15-tetraenoic acid. Biochim Biophys Acta 1967; 137: $184-6$.

24 Holman RT, Johnson SB, Mercuri O, Itarte HJ, Rodrigo MA De Tomas ME. Essential fatty acid deficiency in malnourished children. Am F Clin Nutr 1981; 34: 1534-9.

25 Wolff JA, Margolis F, Bujdoso-Wolff K, Matusick E, MacLean WC. Plasma and red blood cell fatty acid composition in children with protein-calorie malnutrition. Pediatr Res 1984; 18: 162-7.

26 Fernández-Bañares F, Abad-L A, Xiol X, Giné JJ, Dolz C, Cabré $\mathrm{E}$, et al. Vitamin status in patients with inflammatory Cabré E, et al. Vitamin status in patients with infla

27 Fernández-Bañares F, Mingorance MD, Esteve-Comas M, Cabré E, Lachica M, Abade-Lacruz A, et al. Serum zinc, copper and selenium levels in inflammatory bowel disease. Am $\mathcal{F}$ Gastroenterol 1990; 85: 1584-9. 